Article

\title{
Porosity Prediction of Plain Weft Knitted Fabrics
}

\section{Muhammad Owais Raza Siddiqui ${ }^{1,2, *}$ and Danmei Sun ${ }^{1}$}

1 School of Textiles and Design, Heriot-Watt University, Scotland, TD1 3HF, UK;

E-Mail: d.sun@hw.ac.uk

2 Department of Textile Engineering, NED University of Engineering and Technology, Karachi 75270, Pakistan

* Author to whom correspondence should be addressed; E-Mail: mos30@ hw.ac.uk; Tel.: +44-189-689-2238.

Academic Editor: Rimvydas Milasius

Received: 26 November 2014 / Accepted: 19 December 2014 / Published: 30 December 2014

\begin{abstract}
Wearing comfort of clothing is dependent on air permeability, moisture absorbency and wicking properties of fabric, which are related to the porosity of fabric. In this work, a plug-in is developed using Python script and incorporated in Abaqus/CAE for the prediction of porosity of plain weft knitted fabrics. The Plug-in is able to automatically generate 3D solid and multifilament weft knitted fabric models and accurately determine the porosity of fabrics in two steps. In this work, plain weft knitted fabrics made of monofilament, multifilament and spun yarn made of staple fibers were used to evaluate the effectiveness of the developed plug-in. In the case of staple fiber yarn, intra yarn porosity was considered in the calculation of porosity. The first step is to develop a 3D geometrical model of plain weft knitted fabric and the second step is to calculate the porosity of the fabric by using the geometrical parameter of 3D weft knitted fabric model generated in step one. The predicted porosity of plain weft knitted fabric is extracted in the second step and is displayed in the message area. The predicted results obtained from the plug-in have been compared with the experimental results obtained from previously developed models; they agreed well.
\end{abstract}

Keywords: plug-in; porosity; plain weft knitted fabric; multifilament; python script 


\section{Introduction}

Porosity is the ratio of void space within the boundaries of solid material to the total volume of solid material, including void spaces, defined by Guidoin [1]. He developed equations for porosity of solid material in terms of percentage:

$$
\begin{gathered}
\text { porosity }(\%)=100\left[\frac{V_{v}}{V_{t}}\right] \\
\text { porosity }(\%)=100\left[1-\frac{M}{L \rho_{\mathrm{m}}}\right]
\end{gathered}
$$

where $V_{v}$ is volume of void space $\left(\mathrm{cm}^{3}\right) ; V_{t}$ is total volume of porous material $\left(\mathrm{cm}^{3}\right) ; M$ is mass per unit area of porous materials $\left(\mathrm{g} / \mathrm{cm}^{2}\right) ; \rho_{\mathrm{m}}$ is density of solid material $\left(\mathrm{g} / \mathrm{cm}^{3}\right)$ and $L$ is thickness of material $(\mathrm{cm})$.

Benltoufa et al. [2] investigated the different methods for the estimation of the porosity of jersey fabric. They found that the most effective way for the determination of porosity is the use of geometrical modeling. Furthermore, they found that the loop length has more significant effect on porosity of jersey fabric than the stitch density and the thickness of fabric. The proposed model for prediction the porosity of plain knitted fabric by Benltoufa is shown in Equation 3.

$$
\operatorname{porosity}(\varepsilon)=1-\frac{\pi d^{2} l}{4 t C W}
$$

where $t$ is sample thickness; $l$ is stitch length; $d$ is yarn diameter; $C$ is course spacing and $W$ is wale spacing.

Ogulata and Mavruz [3] developed a theoretical model to predict the porosity and air permeability of plain knitted fabric based on D'Arcy's law and they concluded that the air permeability is higher for fabric with lower yarn density (course/cm) and yarn count (Tex).

Angelova [4] developed an experimental procedure for the evaluation of pore size and pore distribution in a single layer woven fabric by using image analysis. Karaguzel [5] developed a structural model for the estimation of pore size of knitted fabric. Peirce's model was used to calculate the stitch length of fabric and yarns were considered circular in cross-section in her research. It showed the clear difference between the model measured and experimental results.

Dias and Delkumburewatte [6] developed a model which was used to predict the porosity of plain weft knitted fabric by using the repeating unit cell of stitch and also analyzed the effect of number of courses, number of wales, fabric thickness, yarn count and fiber density on porosity of plain knitted fabric. They found that the porosity of plain knitted fabric increases with the increase of stitch length and the thickness of fabric. Their theoretical model for porosity of plain weft knitted fabric is shown below.

$$
\text { porosity }(P)=1-\frac{T \times 10^{-5} l}{C W t_{h} \rho_{f}}
$$


where $T$ is the yarn count; $l$ is stitch length; $C$ is Course spacing; $W$ is wale spacing; $t h$ is fabric thickness and $\rho_{f}$ is fiber density.

Abdolmaleki et al. [7] studied the 3D porosity of knitted fabric under different uniaxial extension in course direction. They estimated the porosity of fabric based on the empirical formula developed by Guidoin's [1] and compared the results obtained from Guidoin's empirical formula under different extension with 3D theoretical methods developed by Benltoufa [2] and Karaguzel [5] in their earlier research. They also modified Benltoufa's model due to the fact that it cannot estimate the value close to experimental results under uniaxial extension in course direction of knitted fabric.

Turan et al. [8] developed a method to predict the inter yarn porosity by image analysis. Delkumburewatte and Dias [9] developed a theoretical model, which used to predict the porosity and radius of capillaries of weft knitted spacer fabric based on the geometrical parameters and they found that the porosity and capillary radius of weft knitted spacer fabric influenced by the number of spacer yarn.

In this work a plug-in incorporated in Abaqus/CAE, which can be used to automatically calculate the porosity of plain weft knitted fabric is developed. Plug-in requires only few input parameters to generate 3D geometrical model of a plain weft knitted fabric. Comparisons of porosity of plain knitted fabrics are made between results obtained from plug-in and experiment.

\section{Materials and Methods}

In this work plain weft knitted fabrics made of different yarn, such as monofilament, multifilament and staple fiber, were used in order to evaluate the effectiveness of the developed plug-in. In case of staple fiber yarn intra yarn porosity was also considered in the calculation of porosity. Table 1 shows the fabric specifications of plain weft knitted fabrics. F1 to F4 were unwashed fabrics described by Karaguzel [5]. In her research, the porosity of plain weft knitted fabric is expressed by:

$$
\text { porosity }(\mathrm{P})=1-\frac{\mathrm{S} l \pi \mathrm{R}^{2}}{\mathrm{t}}
$$

where $S$ is the stitch density; $l$ is the stitch length; $R$ is the radius of yarn; and $t$ is the thickness of fabric.

Table 1. Specifications of plain weft knitted fabrics.

\begin{tabular}{cccccccc}
\hline Fabric code & F1 [5] & F2 [5] & F3 [5] & F4 [5] & F5 & F6 & F7 \\
\hline Fiber type & \multicolumn{5}{c}{ Cotton } & \multicolumn{3}{c}{ Polyester } & Polyester \\
Yarn type & \multicolumn{5}{c}{ Staple Fiber } & \multicolumn{3}{c}{ Monofilament } & Multifilament \\
Yarn count (Tex) & 24.61 & 24.61 & 24.61 & 24.61 & 27.00 & 27.00 & 19.0 \\
Yarn radius (mm) & 0.129 & 0.130 & 0.134 & 0.132 & 0.0785 & 0.0785 & 0.16 \\
Wales per cm & 9.00 & 9.00 & 9.00 & 9.00 & 5.40 & 5.40 & 6.40 \\
Courses per cm & 8.00 & 9.00 & 11.0 & 13.0 & 10.6 & 11.8 & 10.6 \\
Stitch length $(\mathrm{mm})$ & 5.137 & 4.916 & 4.53 & 4.119 & 4.725 & 4.6896 & 5.000 \\
Fabric thickness (mm) & 0.52 & 0.53 & 0.53 & 0.56 & 0.512 & 0.507 & 0.72 \\
Areal density $\left(\mathrm{g} / \mathrm{m}^{2}\right)$ & 86.0 & 98.0 & 118.0 & 126.0 & 71.67 & 75.0 & 63.4 \\
Fiber density $\left(\mathrm{g} / \mathrm{cm}^{3}\right)$ & 1.52 & 1.52 & 1.52 & 1.52 & 1.39 & 1.39 & 1.39 \\
\hline
\end{tabular}

Yarn radius $\mathrm{R}$ (in $\mathrm{mm}$ ) can be calculated by the following equation: 


$$
\mathrm{R}=\sqrt{\frac{\mathrm{T}_{\mathrm{y}}}{10^{3} \pi \mathrm{pk}}}
$$

where $T_{y}$ is the yarn count (Tex); $\rho$ is the density of fiber $\left(\mathrm{g} / \mathrm{cm}^{3}\right)$ and $\mathrm{k}$ is the fiber packing fraction in the yarn.

Karaguzel [5] used yarn density of $0.909 \mathrm{~g} / \mathrm{cm}^{3}$ which was used by the Pierce [10] for cotton yarn, due to the fact that the actual values of yarn density are different for both the yarn diameter (width) measured through video microscope and calculated yarn diameter in her research work therefore the actual yarn density values were used for the calculated diameter of yarn in this work in order to calculate the yarn packing fraction.

\subsection{Plug-in}

The Plug-in for the porosity of plain weft knitted fabrics was developed in Abaqus/CAE by using python script. The plug-in comprises two steps/modules, as shown in Figure 1, including:

(1) 3D geometrical model creation of plain weft knitted fabric;

(2) Porosity calculation.

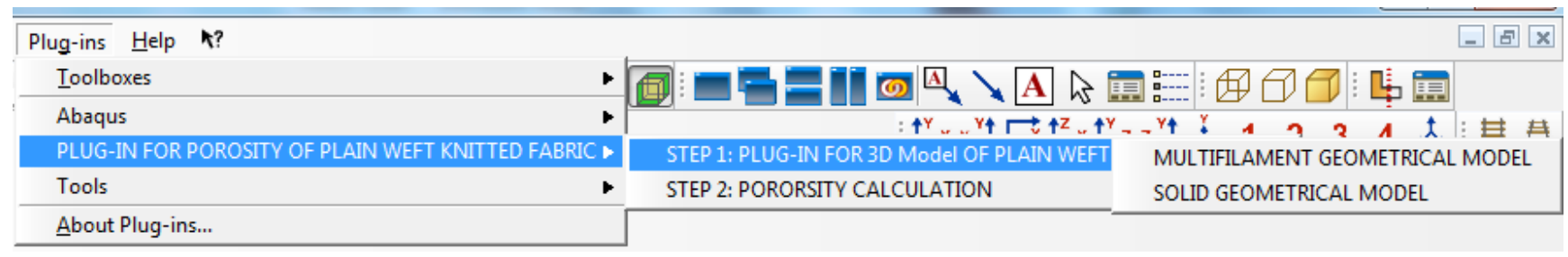

Figure 1. Plug-in for porosity of plain weft knitted fabric.

\subsection{D Model}

Many researchers have proposed the geometrical model of knitted fabric. Pierce [10] developed geometrical models of knitted structures by considering the "yarn axis follows a path composed of circular arcs and straight lines, on a cylindrical surface following the direction of a course". Doyle [11], Shinn [12], Leaf and Glaskin [13], Leaf [14], Munden [15], Postle [16], Kurbak [17], and Demiroz and Dias [18] have also studied the geometrical model of knitted fabrics. Choi and Lo [19] developed a mechanical model of plain knitted fabric through energy approach. Lin et al. [20] developed geometrical models of weft knitted fancy structures on the basis of Non-uniform Rational B-splines (NURBS) curve.

In this work, the 3D model of plain weft knitted fabric is generated by using cubic spline curve to define the central axis of yarn. It is assumed that the circular cross-section of yarn sweeps around the central axis. Central axis of yarn was defined by the nine connecting points which are the function of "e", number of courses and wales per centimeter as shown in Figure 2. Value "e" can be calculated from image analysis.

Figure 3 shows the environment of plug-in which generates 3D solid model of plain weft knitted fabric [21] with two options of model (Pierce and parametric) and up to four limited number of courses and wales are available in the plug-in. Parametric model option based on method described above. 


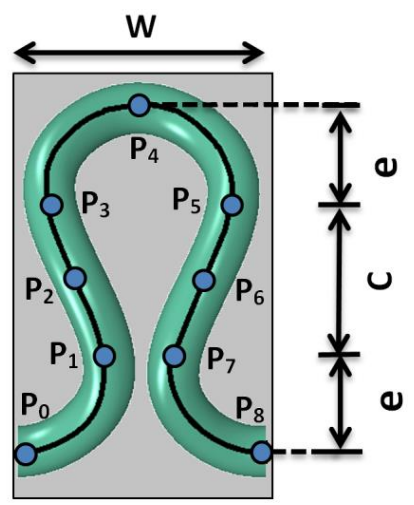

Figure 2. Geometry of a plain weft knitted loop.

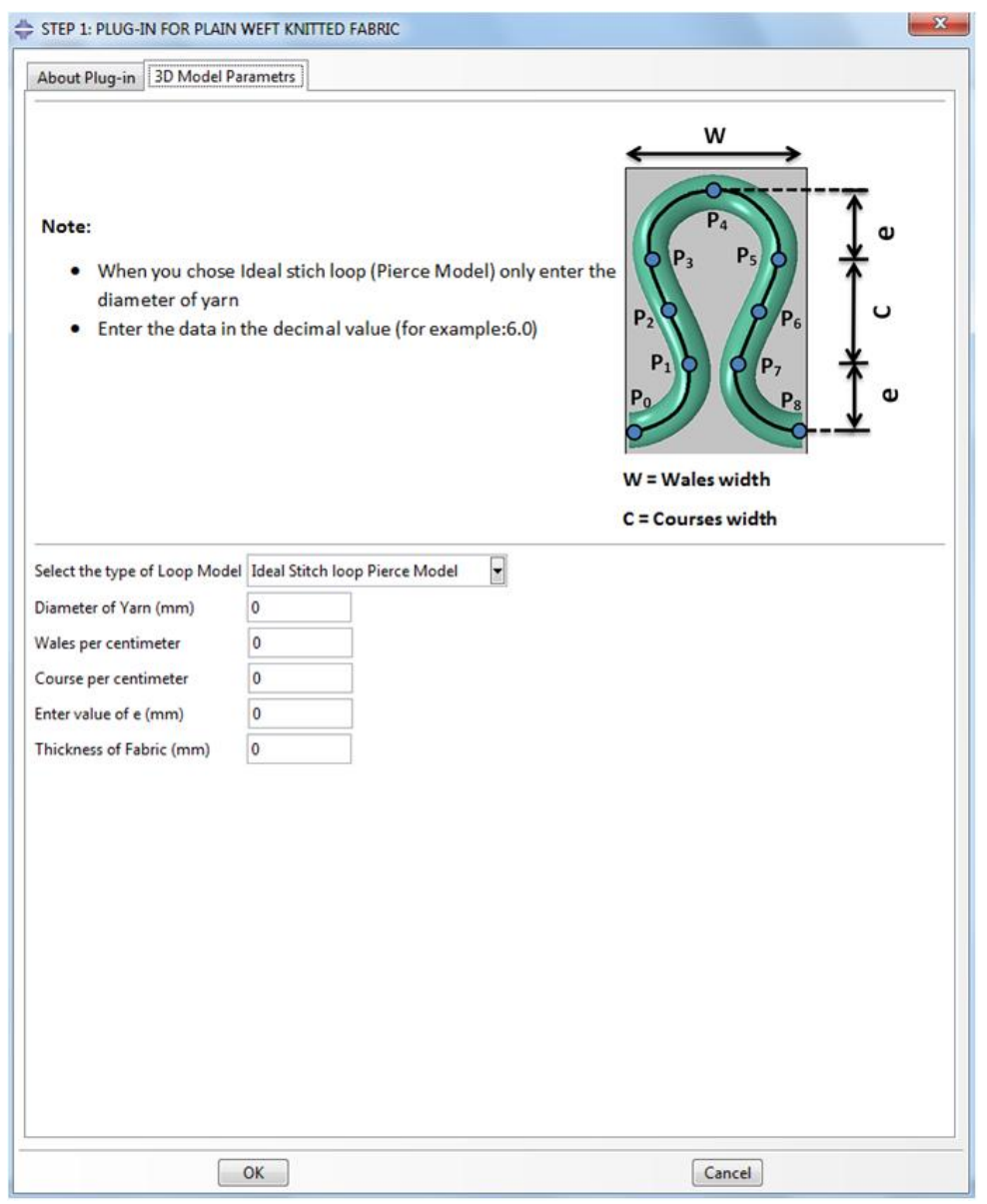

Figure 3. Plug-in user interface for generating solid plain weft knitted fabric geometry.

\subsection{Plug-in for Multifilament Weft Knitted Fabric}

There is a variety of software [22-24] available that can be used to generate weft knitted fabric models in their own environments where yarns are considered as solid. In this work a plug-in was developed which generates multifilament weft knitted fabric in which the filaments are considered individually in a yarn. In this plug-in only parametric model option is available. An idealized packing of circular fibers in yarns was used as described by Schwarz [25], shown in Figure 4. This plug-in requires few more input parameters, such as filament radius $\left(r_{f}\right)$, number of filament in yarn $(\mathrm{N})$ and yarn twist (turns per $\mathrm{cm}$ ) rather than mentioned in Figure 3 to create the 3D model of multifilament weft knitted fabric. 


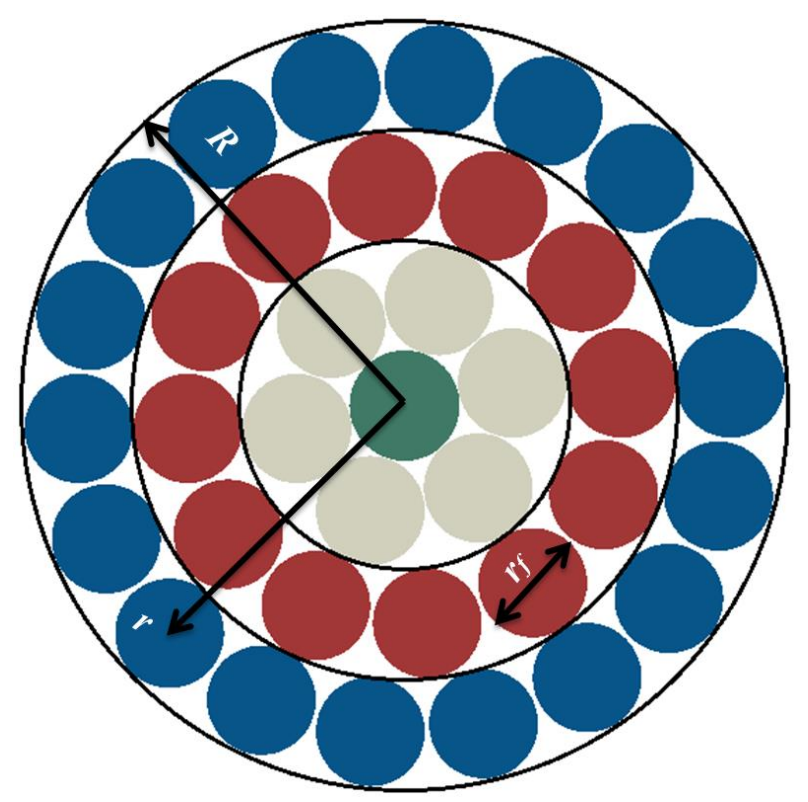

Figure 4. Ideal packing of circular fibers in yarns.

The total number of layers and the radius of each layer were calculated by the Equations (7) and (8) [25], which were built-in in the plug-in.

$$
\text { Number of Layers }=n=\frac{1}{2} \cdot\left(\frac{\text { Yarn Rradius }(R)}{r_{f}}+1\right)
$$

$$
\text { Radius of Centre of } n \text {th Layer }=r=2(n-1) r_{f}
$$

Figure 5 demonstrates 3D Model of weft knitted fabric made of multifilament yarns which can be used for simulation and prediction of heat transfer, air permeability, mechanical properties of fabrics, etc.

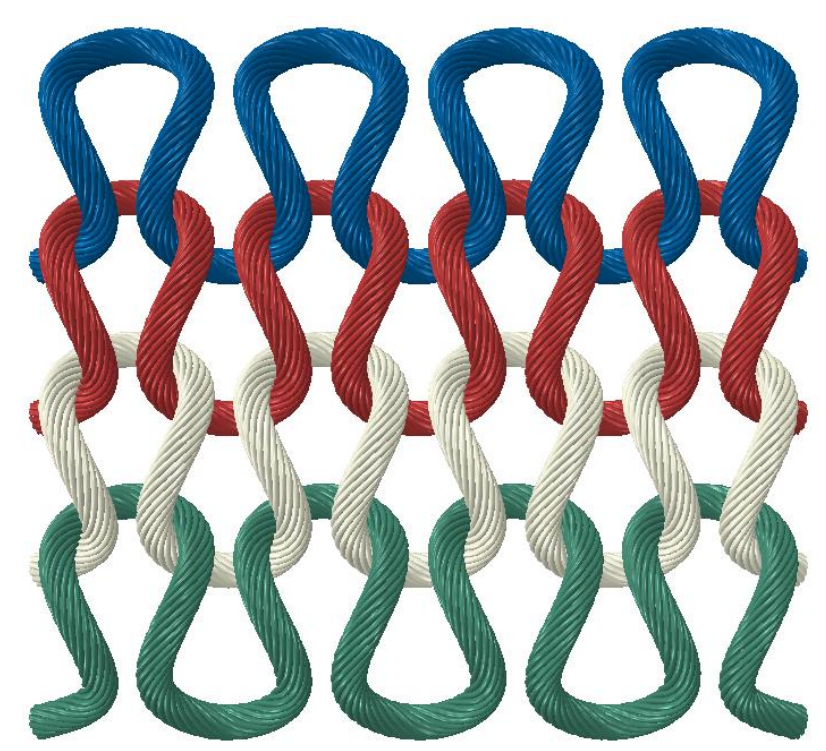

Figure 5. Weft knitted 3D model made of twisted multifilament yarns, created in the developed plug-in. 


\subsection{Prediction of Porosity}

Porosities of plain weft knitted fabrics were calculated in the second step by the unit cell approach. Yarn inter-porosity was also considered due to the fact that the yarn volumetric density with respect to packing fraction of fibers is different for staple fiber yarns. Figure 6 shows the plug-in environment of porosity calculation and equation used for the porosity calculation.

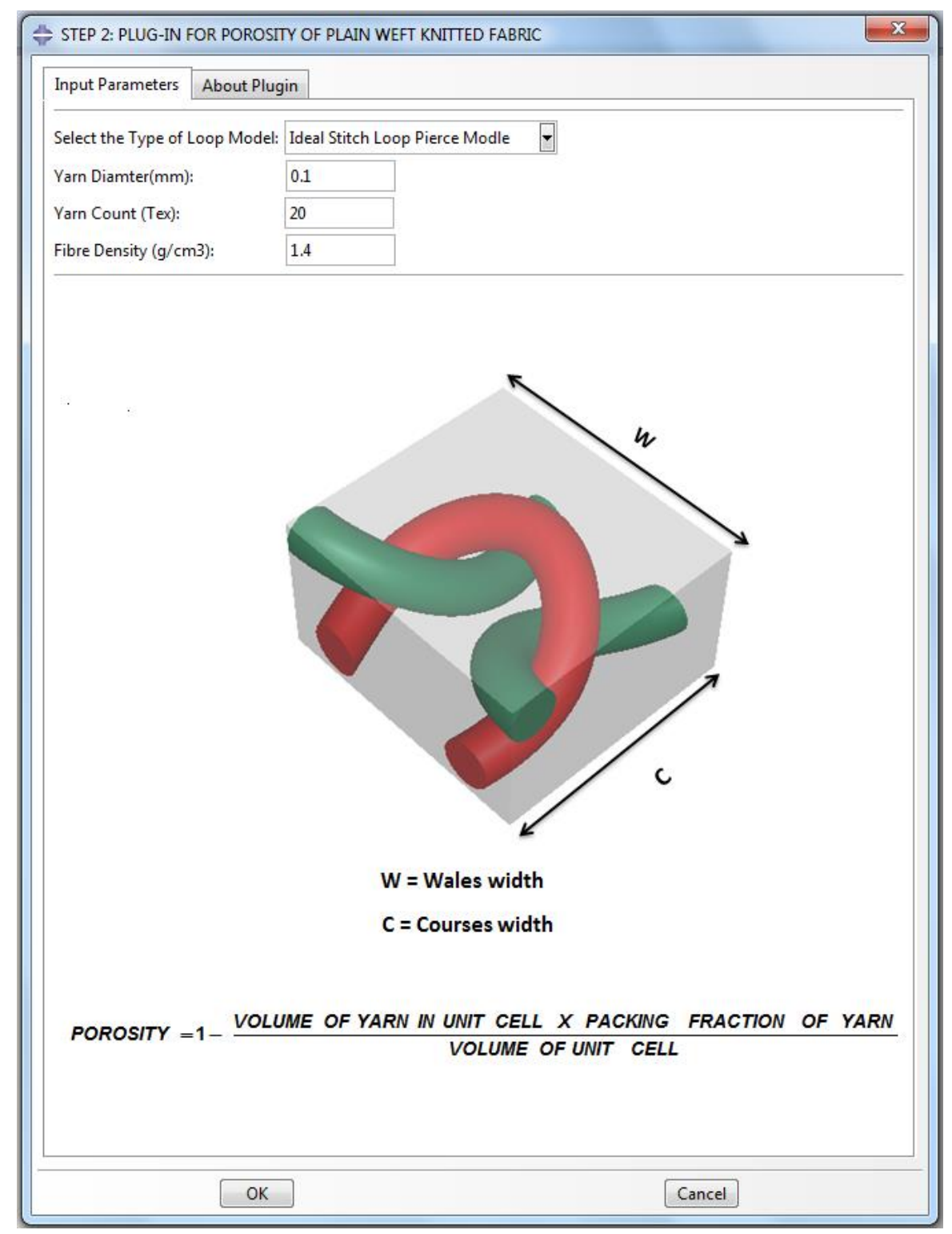

Figure 6. Plug-in for porosity of plain weft knitted fabric.

There are two options available for development of 3D model of weft knitted fabric as solid and multifilament. In case of staple fiber yarn fiber packing fraction is calculated by using Equation (6). A command is used in the script, which extracts the volume of yarn and unit cell. Porosity of the weft knitted fabric calculated in such way is shown in Figure 6. The Calculated value of porosity and fiber volume fraction will be automatically displayed in the message area of Abaqus/CAE, shown in Figure 7. 


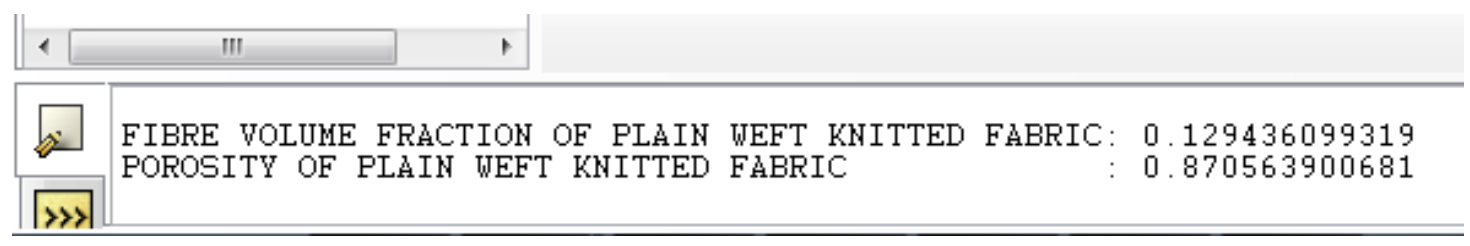

Figure 7. Printed results of porosity in message area of Abaqus/CAE.

\section{Results and Discussion}

Table 2 and Figure 8 show the comparison between the experimental results obtained by using Guidoin's method and predicted results from plug-in in Abaqus/CAE. In this study the porosity of seven different plain weft knitted fabric was calculated. The plain weft knitted fabrics made from different types of yarns including monofilament and multifilament yarns were used in order to evaluate the effectiveness of the developed plug-in. A strong correlation relation (0.964069) and coefficient of determination (0.9294) between results predicted by the developed plug-in and experimental have been found.

Table 2. Comparison of porosity between predicted and experiment.

\begin{tabular}{ccc}
\hline Fabric code & Plug-in predicted & Experiment \\
\hline F1 & 0.8848 & 0.8912 \\
F2 & 0.8787 & 0.8783 \\
F3 & 0.8629 & 0.8535 \\
F4 & 0.86502 & 0.8519 \\
F5 & 0.8977 & 0.8993 \\
F6 & 0.90788 & 0.8936 \\
F7 & 0.93691 & 0.9366 \\
\hline
\end{tabular}

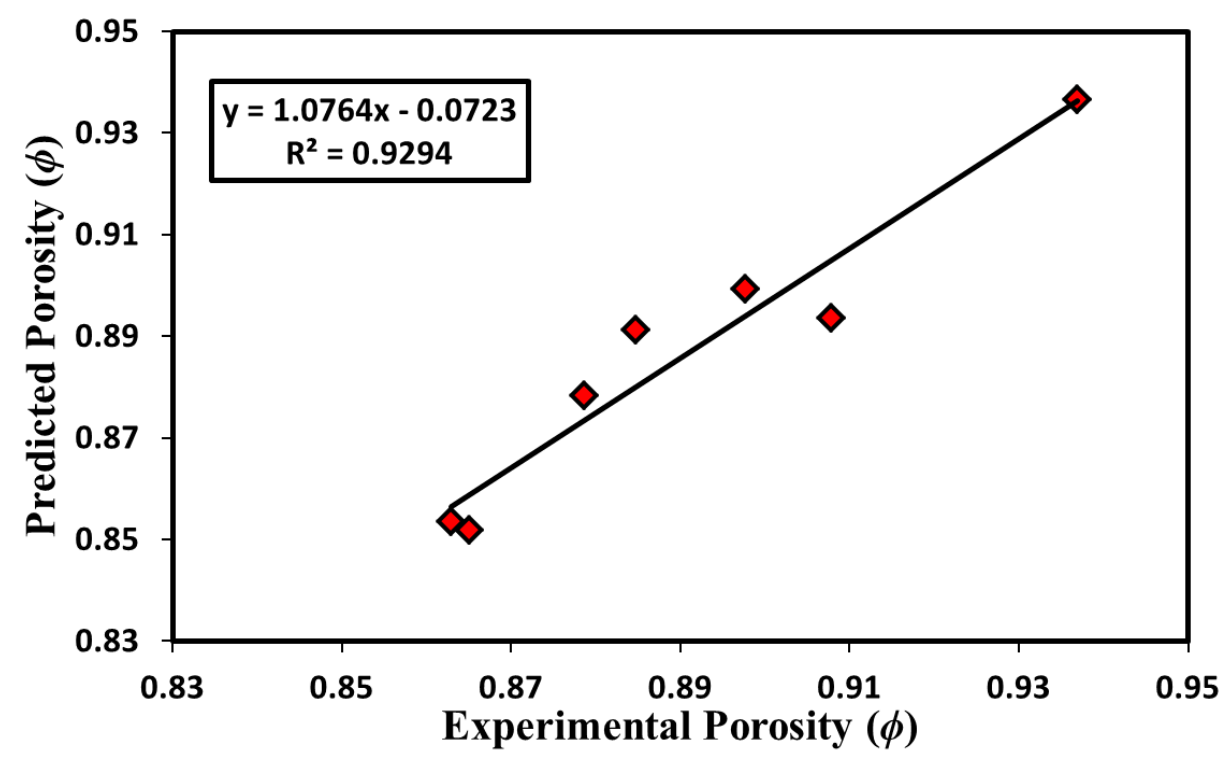

Figure 8. Comparison of porosity between plug-in predicted and experimental.

Furthermore the predicted results were also compared with results made by other methods as shown in Figure 9. It shows the accuracy of porosity obtained from the plug-in, which is very close to the previously developed method. 


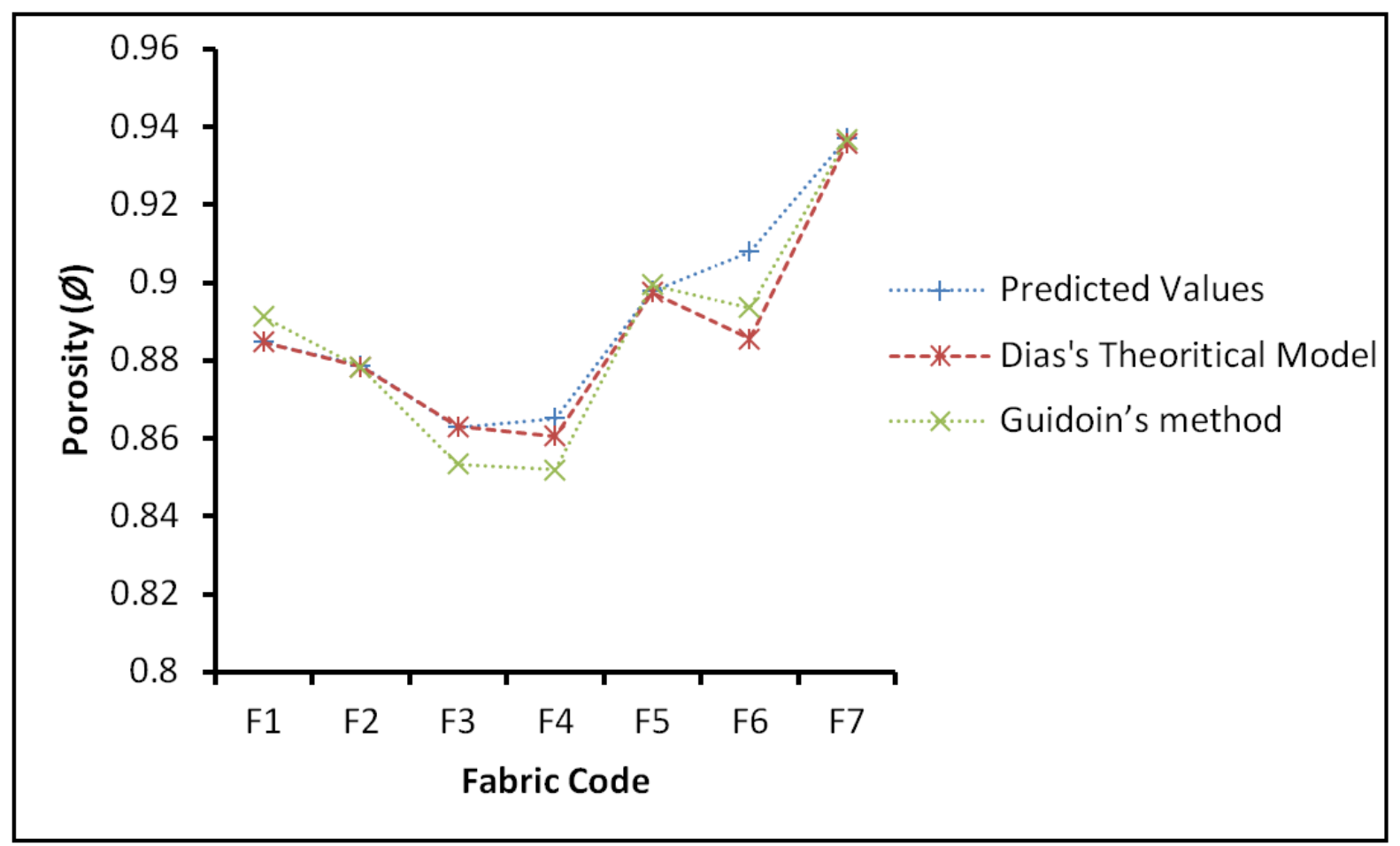

Figure 9. Porosity comparison of plug-in predicted results with other methods.

\section{Conclusions}

A Plug-in was successfully developed which enables to calculate the porosity of plain weft knitted fabrics. It was developed in Abaqus/CAE by using python scripting which required only few input parameters to automatically calculate the porosity of plain weft knitted fabric. Three-dimensional geometric models of plain weft knitted fabrics were developed by using the actual parameters of the fabric. A strong correlation has been obtained between the experimental results and the Plug-in predicted values of fabric porosity, showing the applicability of the developed plug-in. Moreover a plug-in was successfully developed to generate 3D geometric models of weft knitted fabrics made of twisted and untwisted multifilament yarns. It can be used for simulation and prediction of many different properties of plain weft knitted fabric.

\section{Acknowledgments}

This research is financially supported by NED University of Engineering and Technology, Karachi, Pakistan.

\section{Author Contributions}

All authors were equally contributed, read and approved the final manuscript.

\section{Conflicts of Interest}

The authors declare no conflict of interest. 


\section{References}

1. Guidoin, R.; King, M.; Marceau, D.; Cardou, A.; de la Faye, D.; Legendre, J.M.; Blais, P. Textile arterial prostheses: Is water permeability equivalent to porosity? J. Biomed. Mater. Res. 1987, 21, 65-87.

2. Benltoufa, S.; Fayala, F.; Cheikhrouhou, M.; Nasrallah, S.B. Porosity determination of jersey structure. Autex Res. J. 2007, 7, 63-69.

3. Ogulata, R.T.; Mavruz, S. Investigation of porosity and air permeability values of plain knitted fabrics. Fibres Text. East. Eur. 2010, 18, 71-75.

4. Angelova, R.A. Determination of the pore size of woven structures through image analysis. Cent. Euro. J. Eng. 2012, 2, 129-135.

5. Karaguzel, B. Characterization and Role of Porosity in Knitted Fabrics. M.S. Thesis; North Carolina State University: Raleigh, NC, USA, 2004.

6. Dias, T.; Delkumburewatte, G.B. The influence of moisture content on the thermal conductivity of a knitted structure. Measure. Sci. Tech. 2007, 18, 1304-1314.

7. Abdolmaleki, S.; Jeddi, A.A.A.; Amani, M. Estimation on the $3 \mathrm{D}$ porosity of plain knitted fabric under uniaxial extension. Fibers Polym. 2012, 13, 535-541.

8. Turan, R.B.; Okur, A.; Deveci, R.; Açikel, M. Predicting the intra-yarn porosity by image analysis method. Text. Res. J. 2012, 82, 1720-1728.

9. Delkumburewatte, G.B.; Dias, T. Porosity and capillarity of weft knitted spacer structures. Fibers Polym. 2009, 10, 226-230.

10. Peirce, F.T. Geometrical principles applicable to the design of functional fabrics. Text. Res. J. 1947, 17, 123-147.

11. Hurd, J.C.H.; Doyle, P.J. Fundamental aspects of the design of knitted fabrics. J. Text. Inst. Proc. 1953, 44, 561-578.

12. Shinn, W.E. An engineering approach to jersey fabric construction. Text. Res. J. 1955, 25, 270-277.

13. Leaf, G.A.V.; Glaskin, A. The geometry of a plain knitted loop. J. Text. Inst. Trans. 1955, 46, T587-T605.

14. Leaf, G.A.V. Models of the plain-knitted loop. J. Text. Inst. Trans. 1960, 51, T49-T58.

15. Munden, D.L. The geometry and dimensional properties of plain-knit fabrics. J. Text. Inst. Trans. 1959, 50, T448-T471.

16. Postle, R. Dimensional stability of plain-knitted fabrics. J. Text. Inst. 1968, 59, 65-77.

17. Kurbak, A. Plain knitted fabric dimensions (Part II). Text. Asia. 1998, 29, 36-44.

18. Demiroz, A.; Dias, T. A study of the graphical representation of plain-knitted structures part I: Stitch model for the graphical representation of plain-knitted structures. J. Text. Inst. Trans. 2000, 91, 463-480.

19. Choi, K.F.; Lo, T.Y. An energy model of plain knitted fabric. Text. Res. J. 2003, 73, 739-748.

20. Li, Y.L.; Yang, L.H.; Chen, S.Y.; Yuan, J.; Li, N.N. 3D modeling and simulation of fancy fabrics in weft knitting. J. Donghua Uni. Engl. Ed. 2012, 29, 351-358.

21. Siddiqui, M.O.R.; Sun, D. Automated model generation of knitted fabric for thermal conductivity prediction using finite element analysis and its applications in composites. J. Indust. Text. 2014, doi: $10.1177 / 1528083714551440$. 
22. TexGen software. Available online: http://www.texgen.sourceforge.net (accessed on 1 March 2012).

23. TexEng Software Ltd. Available online: http://www.texeng.co.uk/ (accessed on 1 March 2012).

24. WiseTex Software. Available online: https://www.mtm.kuleuven.be/Onderzoek/Composites/software/ wisetex (accessed on 1 April 2013).

25. Schwarz, E.R. Certain aspects of yarn structure. Text. Res. J. 1951, 21, 125-136.

(C) 2014 by the authors; licensee MDPI, Basel, Switzerland. This article is an open access article distributed under the terms and conditions of the Creative Commons Attribution license (http://creativecommons.org/licenses/by/4.0/). 